\title{
Ticari İmar Adalarında Planlı Tip Distance Yaklaşımına Göre İmar Çapı Gösterimi
}

\author{
Selim Taşkaya* \\ Artvin Meslek Yüksekokulu, Mimarlkk ve Șehir Planlama Bölümü, Artvin, Türkive
}

İstanbul Sabahattin Zaim Üniversitesi Fen Bilimleri Enstitüsü Dergisi (2021) 3 (3): 204-211

https:// doi. org/10 47769/1zufbed.1016567

(iD) ORCID ${ }^{1}$ 0000-0002-4290-3684

\section{YAYIN BILGISİ}

Yayın geçmişi:

Gönderilen tarih: 30 Ekim 2021

Kabul tarihi: 17 Kasım 2021

\section{Anahtar kelimeler:}

Ticaret İmar Adası

Distance Yöntemi

İmar Çap

\section{ÖZET}

Ülkemizde bir alanı tümsel yaşam standartlarına uygun hale getirmek için imar çalışmaları başlığında faaliyetlerde bulunulur. Ülke kalkınma planları üst ölçekten, uygulama imar planları olan alt ölçeğe doğru imar planlarının oluşturulmasında bir hiyerarşi vardır. Bu hiyerarşi ile birlikte 1/1000'lik imar planlarında, özellikle bir bölgede yaşayan insanların alışveriş ihtiyacını karşılamak üzere belirlenen imar sınırları içerisinde ticaret adaları tayin edilir. Ticari imar adaları farklı yapı nizamları, emsal ya da bina yüksekliklerinde olabilirler. İmar sınırları içerisinde ayrık, blok ve bitişik esas olmak üzere farklı tipte oturum alanlarının olabileceği muhtemel yapı nizamları mevcuttur. Bu yapı nizamları ile kimlikleri belirlenen imar adalarındaki mevcut imar parsellerine inşaat izni verilebilmesi işlemi ise imar çapıdır. İmar çapları, planlı alanlar tip imar yönetmeliği ve plan notları çerçevesince verilir. Adanın emsal, yükseklik, yapı nizamına göre imar çapı verilme işlemi yapılır. Distance yöntemi ise, ilgili imar adalarındaki temiz imar parsellerine inşaat izni verilebilmesi amaciyla parselin geometrik durumuna göre konveks şekillerin gerek kare ya da dikdörtgen gibi, çekme kuralları ile doğru oturum alanının meydana getirilmesi işlemidir. Çalışmamızda, mesafe yaklaşımı ile, tabandaki oturum alanlarının nasıl verilebileceği hangi yapı nizamı hangi emsal ve yükseklikteki konveks parsellere nasıl işlem uygulanacağı gösterilmeye çalışıldı.

\section{Display of Zoning Diameter According to the Planned Type Distance Approach on Commercial Zoning Islands}

\begin{tabular}{l}
\hline ARTICLE INFO \\
\hline Article history: \\
Received: 30 October 2021 \\
Accepted: 17 November 2021 \\
\hline Key words: \\
Trade Reconstruction Island \\
Distance Method \\
Zoning Diameter \\
\end{tabular}

\begin{abstract}
In our country, activities are carried out under the title of zoning studies in order to make an area suitable for holistic living standards. There is a hierarchy in the formation of zoning plans from the upper scale of the country development plans to the lower scale, which are the implementation zoning plans. With this hierarchy, in the 1/1000 zoning plans, trade islands are designated within the zoning boundaries determined to meet the shopping needs of the people living in a region. Commercial zoning islands can have different building regulations, precedent or building heights. There are possible building regulations within the zoning boundaries, where there may be different types of sitting areas, such as split, block and adjacent basis. The process of granting construction permits to the existing zoning parcels in the zoning islands, whose identities are determined by these building regulations, is the zoning scale. Zoning diameters, planned areas are given within the framework of type zoning regulations and plan notes. The zoning diameter is given according to the precedent, height and building order of the island. Distance method, on the other hand, is the process of creating the right residential area with the drawing rules of convex shapes, such as square or rectangular, according to the geometric condition of the parcel, in order to be able to give construction permits to the clean zoning parcels in the relevant zoning islands. In our study, it has been tried to show how the settlement areas at the base can be given, which building order, which precedent and how to apply the process to the convex parcels with the distance approach.
\end{abstract}




\section{Giris}

İmar sözü, Arapça ümrandan (düzenlilikten) gelir. Sözlük anlamı; bayındır kılma, şenlendirme, onarmadır (Aksay,2005). Yaşam alanlarımıza ait üretilen imar planlarının genel hedefi kamu yararıdır. İmar planları ile düzenlemeye sokulan alanlarda arazilerin kamu yararına en faydalı kullanımları tespit edilir. Ülkemizdeki mevcut imar tüzesi uyarınca yapılan arazi ve arsa düzenleme çalışmalarında, değer tespitine ilişkin hükümleri içermediğinde uygulama öncesi parsellerin objektif ölçütlere göre değerlendirilememesi, parsellerin yeniden tahsisi için yapılan dağıtım aşamasında değer farklılıkları oluşmakta mevzuat ve uygulama açısından yetersiz kalmaktadır. Arazi ve arsa düzenleme çalışmaları, uygulama bölgesindeki mevcut kadastro yapısını imar planı ile değişime zorlamaktadır. Dolayısıyla, yapılan uygulama ile sadece o bölge içerisindeki kadastral parsel sınırları değil, mülkiyete ait mevcut ekonomik değerler de değişime uğramaktadır (Frızzell 1979).Bu sayede imar planlarıyla kanun ve mevzuatlarla korunan kullanımların en uygun şekilde tasarruf edilmesi sağlanacaktır (Karaağaç, 2019). Modern ve sağlıklı kentler için imar planları olmazsa olmaz bir öneme sahiptir. İmar planları, mevcut mülkiyet yapısı ile ilişkilendirilebildiği ve araziye tatbik edildiği sürece esas amacına ulaşan yasal dokümanlardır. $\mathrm{Bu}$ nedenle, ülkemizde çeşitli imar uygulama yöntemleri geliştirilerek, imar planları ile mülkiyet ilişkisi sağlanmakta, modern ve sağlıklı kentlerin olușması ve kanuna aykırı bir șekilde ortaya çıan yapılaşmış alanların da rehabilite edilmesi amaçlanmaktadır (Terzioğlu, 2015). Bir kentin sağlıklı bir şekilde gelişmesinin en önemli şartı; imar dokusunun, şehircilik ilkelerinin ve planlama esaslarının kamu yararına uygun olmasıdır. İmar planı hükümleri doğrultusunda sağlıklı gelișmiş kentlerin ise insan yaşamını kolaylaştırdığı açıktır. Bunun yanında gerçekleştirilen imar planı uygulamaları mülkiyet olgusu ile de yakından ilişkilidir. $\mathrm{Bu}$ nedenlerden dolayı, bir yerleşim bölgesindeki kullanım kararlarını belirleyen imar planlarının kamu yararını en üst seviyede tutarak belirlenmesi ve bu husus gözetilerek de imar planı uygulamalarının yapılmas1 gerekmektedir [Ergen,2006]. Arazi ve arsa düzenlemesi (AAD) şehir planlaması açısından kullanışsız yapıya sahip kadastro parsellerinin daha ekonomik kullanılabilir bir yapıya dönüşümünü sağlayan bir imar planı uygulama aracıdır. Arazi ve arsa düzenlemesinde temel ilke, bir düzenleme bölgesindeki mevcut kadastro parsellerinin tek bir kütle haline getirilerek, imar planı

\section{Materyal ve Yöntem}

Distance Yöntemi, arsa ve arazi düzenlemelerinin bitirildiği imar adası üzerinde yer alan parsellere uygun inşaat hesaplamasının yapılabilmesi için parsel şekline göre konveks geometri şekil formülleri sayesinde bina oturum alanın çekme mesafeleri ile belirlenmesini sağlayan işlem adımları dizisidir.

Eşitsizlik teorisi çalışmalarında daha genel ve yeni sınırlar bulmak için çalışma yapılan fonksiyon sınıfi için hipotez şartlarında kısıtlama yapılabilir veya ek bazı özellikler getirilerek sonuçların kullanım alanları genişletilebilir. Çünkü fonksiyonlar aynı anda birçok özelliği sağlayabilir ya da bazı fonksiyon sınıfları birbirleriyle belirli özellikler yönüyle benzerlik gösterebilir. Yapılan çalışmalarda farklı türden konveks fonksiyonlar 19 için ispatlanan integral eşitsizliklerin, belli özel şartlar için farklı konvekslik sınıfları içinde sağladığı görülür (Kaplan, 2016). Dolayısıyla buradan konveks fonksiyonlar arasında özellikleri açısından bir hiyerarşi olduğu gerçeğine ulaşılır. Ancak bu hiyerarşide bütün konvekslik sınıflarını birlikte ele almak zor olduğundan aralarındaki ilişki, tanımları ve özellikleri kullanılarak şu şekilde oluşturulabilir (Kaplan, 2016). verilerine uygun olarak yeni imar parselleri şeklinde düzenlenmesi ve yeniden mal sahiplerine geri verilmesidir. $\mathrm{Bu}$ uygulama sonucunda kamuya ait alanların da kamu hizmetine sunulması sağlanmaktadır [Yomralıoğlu, 1992]. Arazi ve arsa düzenlemesinin genel esasları 3194 sayılı İmar Kanununun 18 ve 19. Maddeleri ile uygulamaya ilişkin esaslar ise 3194 sayılı İmar Kanununun 18. Maddesi Uyarınca Yapılacak Arazi ve Arsa Düzenlemesi ile İlgili Esaslar Hakkında Yönetmelik hükümleriyle düzenlenmiştir. Uygulamada tereddüt konusu olan bazı hususlar da Danıștay içtihatları ile açıklığa kavuşturulmuştur [Karavelioğlu, 2002]. Arazi ve arsa düzenlemesinin yapılabilmesi için öncelikle uygulama yapılacak alanın belirlenmesi gerekmektedir. Düzenleme sınırı belirlenirken, şehrin gelişme yönü ve yoğun yapılaşmaya uygun öğeleri göz önünde bulundurulur. Ardından Belediye ve mücavir alan sınırları içinde belediye encümeni, dışında ise il idare kurulunca düzenleme sınırının tespitine ilişkin karar alınır. [Çelik, 2006]. Planlama yaklaşımlarında yaşanan değişimlerin özellikle gelişim sürecinde olan ülkelerde plan kavramlarının artmasına ve neticesinde her grubun kendi planını üretmesine sebep olmaktadır (Ayrancı, 2013). Düzenleyici planlama sisteminde plan ve uygulama birbirlerini takip eden iki süreçtir (Ünal, 2008). Parselasyon planları kesinleştikten sonra tescillenmesi için, ilgili belediyelerin Tapu ve Kadastro Müdürlüklerine gerekli belgeler teslim edilir ve artık mülkiyet bu belgelere göre belirlenir (Bıylk ve Uzun, 1997). Uygulayıcılar; belediyeler ve mücavir alan sınırları dahilinde ise ilgili belediyeler, bu alanlar dışında ise valiliklerdir. Bunların yanı sira yasalarla kendilerine imar uygulaması yapma yetkisi verilen diğer idarelerdir. (Uzun, 1992). Ülkemizde kentsel planların çerçevesinde, 1/100.000 lik çevre düzeni planları ile şehirlerde gelişime açık bölgelerin 5000 yada 2000 lik nazım imar planlarının, yerel yönetimler aracılığıyla 1000 lik uygulama planlarına dönüştürülerek, imar ve şehircilik faaliyetlerinin kanun ve yönetmelikler ışığında dürüstlük ve uygunluk ilkeleri doğrultusunda uygulanması amaç edinilmiştir (Taşkaya,2019). Hızlı kentleşme plansız gelişmeyi beraberinde getirmiştir. Bu süreç, sosyal ve teknik donatı alanları yetersiz, ulaşım planlaması yapılamamış, sanayi tesislerinin yaşam ve dinlenme alanları ile iç içe olduğu bir kent dokusunu ortaya çıkarmıştır (Taşkaya, 2019).

$I \subseteq \mathbb{R}$ olmak üzere, Log -konveks fonksiyonlar sınıfı, konveks fonksiyonlar sinıfi, quasi -konveks fonksiyonlar sinıfi, p fonksiyonlar sınıfi ve Godunova-Levin fonksiyonlar sınıfı sırasıyla $\mathscr{L}(I), \mathrm{C}(\mathrm{I}), \mathrm{QC}(\mathrm{I}), \mathrm{P}(\mathrm{I}), \mathrm{Q}(\mathrm{I})$ ile gösterilirse; $\mathscr{L}(I) \subset \mathrm{C}(\mathrm{I}) \subset \mathrm{QC}(\mathrm{I}) \subset$ $\mathrm{P}(\mathrm{I}) \subset \mathrm{Q}(\mathrm{I})$ olduğu görülür (Kaplan, 2016).

$f: \Delta \rightarrow \mathbb{R}$ fonksiyonu $\forall(x, y),(z, w) \in \Delta$ ve $\lambda \in[0,1]$ olmak üzere eğer $f(\lambda x+(1-\lambda) z, \lambda y+(1-\lambda) w) \leq \lambda f(x, y)+(1-\lambda) f(z, w)$ oluyorsa f'ye $\Delta$ üzerinde konvekstir denir (Dragomir 2001). $\forall x \in[\alpha$, $b]$ ve $\forall y \in[c, d]$ için eğer $f y:[\alpha, b] \rightarrow \mathbb{R}, f y(u)=f(u, y)$ ve $f x:[c$, d] $\rightarrow \mathbb{R}, f x(v)=f(x, v)$ Kısmi dönüşümleri konveks ise $f: \Delta \rightarrow \mathbb{R}$ fonksiyonu koordinatlarda konvektir (Kaplan, 2016).

(Koordinatlarda Konveks Fonksiyon): $f: \Delta \rightarrow \mathbb{R}$ fonksiyonu verilsin. Eğer $f(t x+(1-t) y, s v+(1-s) w) \leq t s f(x, u)+s(1-t) f(y, u)$ $+t(1-s) f(x, w)+(1-t)(1-s) f(y, w)$ eşitsizliği $\forall t, s \in[0,1]$ ve $(x, u),(x, w),(y, u),(y, w) \in \Delta$ için sağlanıyorsa (Kaplan, 2016) $f$ 'ye $\Delta$ üzerinde koordinatlarda konveks fonksiyon denir (Latif and Alomari 2009b). 


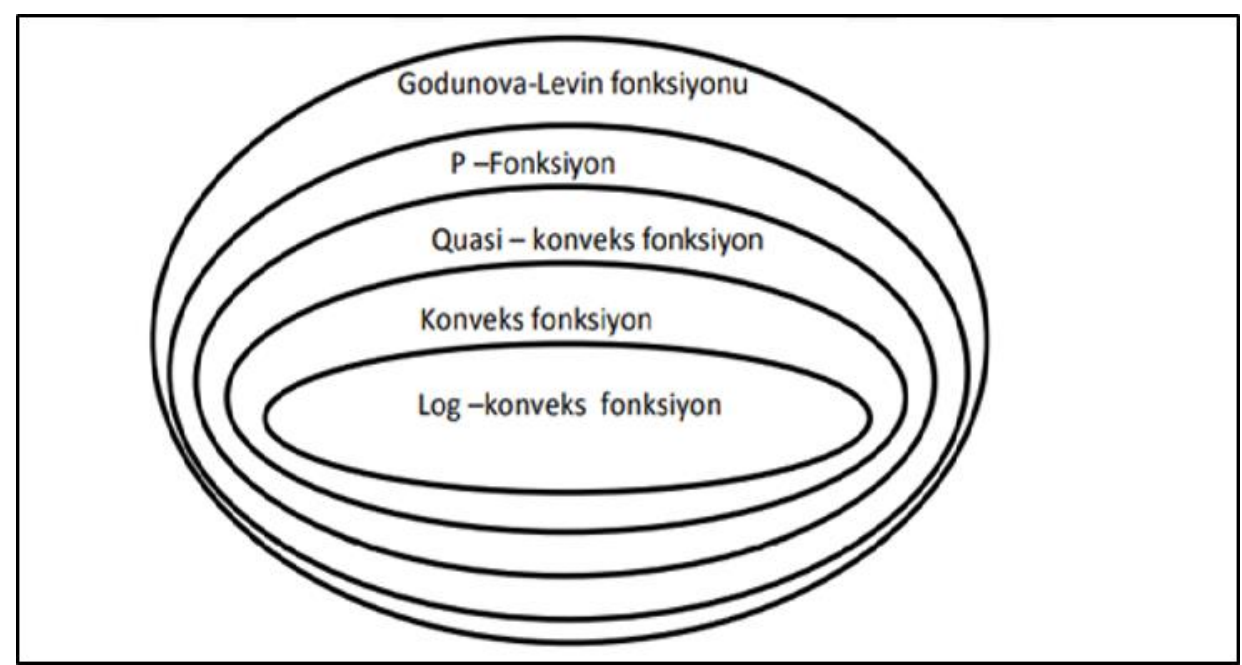

Şekil 1. Godunova -levin fonksiyonu, P -fonksiyon, Quasi- konveks fonksiyon, Konveks fonkiyon ve Log -konveks fonksiyn sınıflarının ilişkisi (Kaplan, 2016).

\section{Bulgular ve Tartıșma}

Vatandaş ya da resmi kurumlar bir arazi üzerine inşaat yapabilmesi için, belediye imar ve mücavir alan sınırları içerisinde belediyelerden, belediye imar ve mücavir alan sınırları dışında ise özel il idarelerinden izin almak durumundadır (İmar Kanunu, 2019; Taşkaya, 2019). Kadastral bir parsel ise ilgili taşınmaz, yani 18. madde uygulaması ve tevhit ifraz, yola terki ya da yoldan ihdas1 yapılmamışsa, kesinlikle bu haliyle inşaat için izin verilemez (İmar Kanunu, 2019). Parsel, normal imar sınırları içerisinde arsa şekline, imar sınırları dışında ise en az bir yola cephesi olacak şekilde yola terksiz ya da ihdassız şekilde olursa inşaat için izin verilir (İmar Kanunu, 2019; Taşkaya, 2019).

İnşaatın yapı cinsi, konut, ticaret, sanayi, konut+ticaret ya da imar sınırları dışında bağ bahçe alanları veya imar mücavir sınırları dışında ne yapılacaksa yapılsın, ilk işlem adımı imar çapıdır. İmar çap1, ulusal koordinat ya da yerel koordinat sisteminde, planlı tip ya da plansız tip alanlar yönetmeliği çerçevesinde, yapı nizamına uygun olarak çekme mesafelerinin verilmesi işlemidir. İmar çapı bir arsaya verildikten sonra, proje aşamasına geçilir. Bir yerde inşaat yapılabilmesi için temel başlangıç imar çapıdır (Taşkaya, 2019). İmar çapları ayrık, bitişik ve blok nizamda olmak üzere 3 ana eksende verilir. Halihazır arazi üzerinden alınan cephe, derinlik ve köşe koordinatları ile gelen ham datalar plan üzerinde nereye denk geliyorsa, o planın yapı nizamına göre çekme mesafeleri verilir (Taşkaya, 2019). Bunlar arasındaki mekanik sonuçlara göre şekil değişimleri, düğüm ve vektör analizleri incelenip mukayese edilebilir (Taşkaya;Taşkaya, 2019). Geometrik şekilleri aynı mesnetleri farklı ve geometrik şekilleri farklı mesnetleri aynı yapılar karşılaştırılmalı incelendi (Taşkaya;Taşkaya, 2019).

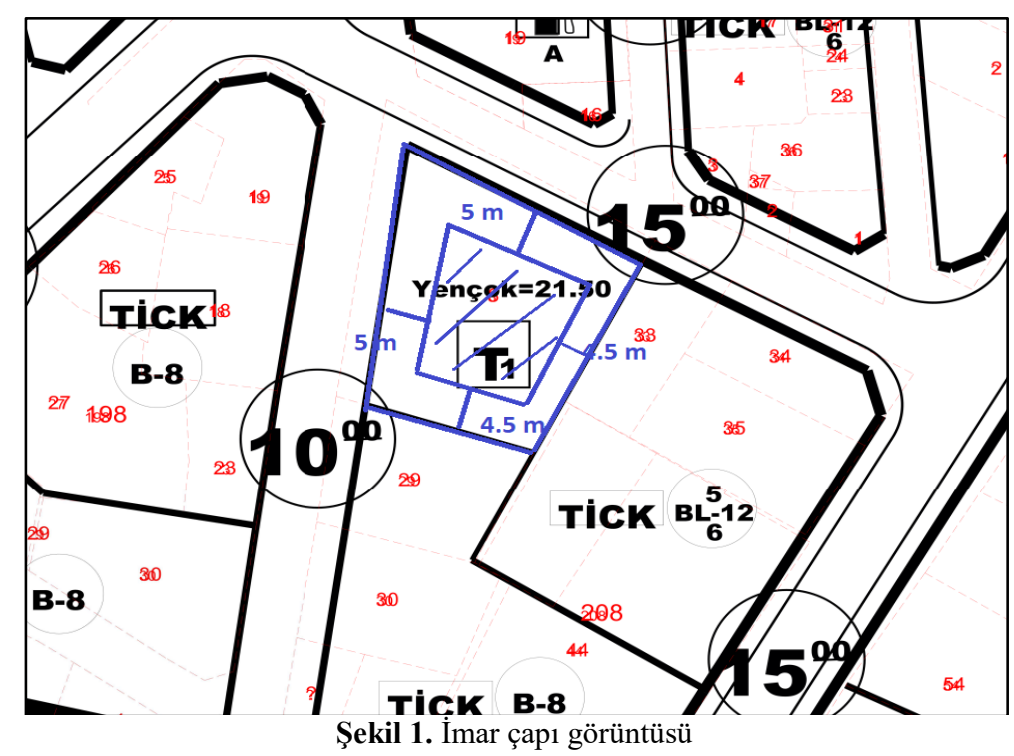

Şekil 1.de, T1 lejantında yani yüzde yüz ticaret alanı olan parsel de yükseklik en çok 21.50 metre olacağı imar planına işlenmiştir. Ortalama daire başına yükseklik metre alınacağından köşe başında her iki cephesi yola baktığından ön çekme mesafesi 5 metre olarak mesafe yaklaşımı ile çekildi. Diğer komşu parsellerin tarafından ise planlı tip imar yönetmeliği çerçevesince 4 kata kadar yan bahçe mesafesi 3 metre sonrasında 4 kattan sonra kat başına yarımşar metre artacağından 7 kata tekabül eden 4.5 metre çekilerek bina oturumunun yapılması için imar çapı gösterilmiştir. 


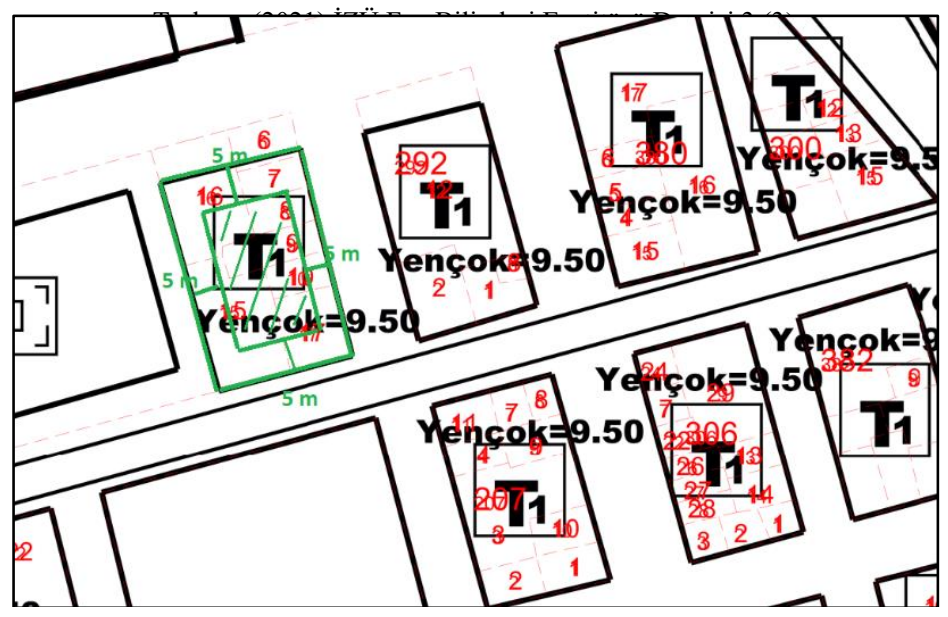

Şekil 2. İmar çap1 görüntüsü

Şekil 2.de, tek bir ada tek bir parsel bazında bina oturum alanının oluşabilmesi için 3 kata kadar müsaadeli tamamı ticari olarak kullanılacak parselde aksi bir belediye meclisli plan notu yok ise 4 bir tarafı yola baktığından 5 er metre çekilerek imar çapı gösterilmiştir

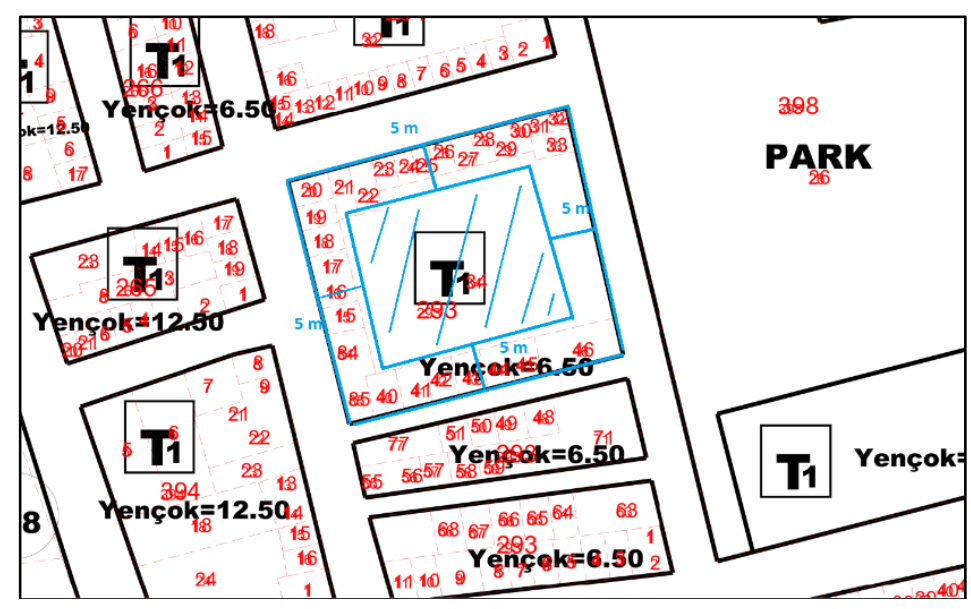

Şekil 3. İmar çap1 görüntüsü

Şekil 3.de, yüksekliği 6.50 metre olan tek ada bazındaki parsel yine 4 bir tarafı yola baktığından dolayı ön çekme mesafesi 5 er metre çekilerek genelden özele mesafe yaklaşımı mantığıyla imar çapı gösterilmiştir

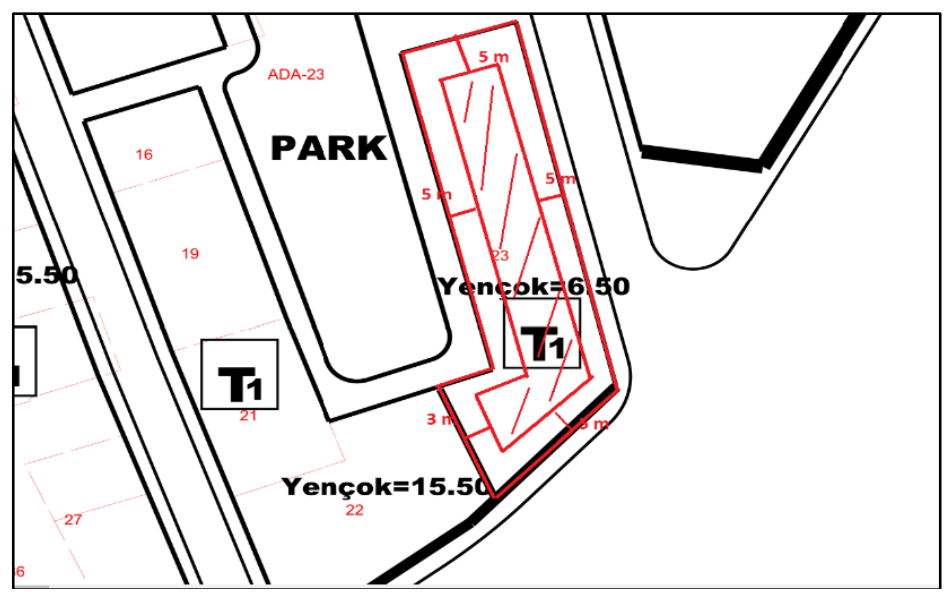

Şekil 4. İmar çap1 görüntüsü

Şekil 4.de, zemin artı bir 2 kata müsaadeli bu 2 katın tamamının ticari amaçlı kullanılacağı baz alındığında 3 tarafi yola cepheli olduğundan ön çekme mesafesi 5 er metre, komşu olduğu parselden ise yan bahçe mesafesi 3 metre çekilerek mesafe yaklaşımı yapılıp imar çapı gösterilir. 


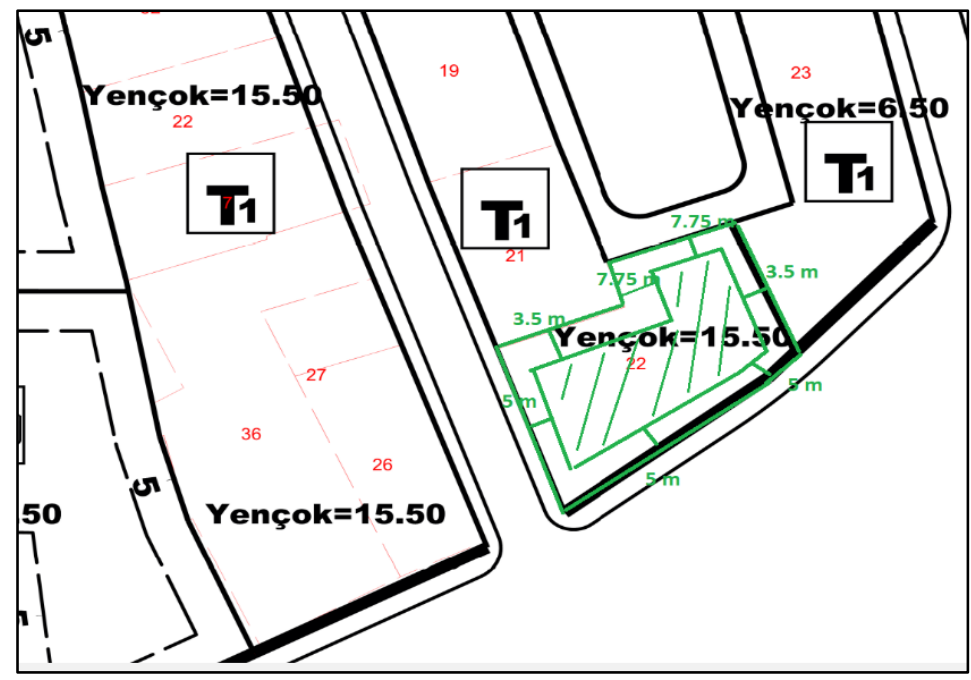

Şekil 5. İmar çap1 görüntüsü

Şekil 5.de, özellikle yerleşim birimlerinin merkezlerinde kapalı çarşı, iş hanı gibi yapıların oluşumu için imar planlarına işlenen ticaret alanından 5 katlı bir parsel de, imar çapı verilmeye çalışılmıştır. Buradan yola bakan taraflarda aksi plan notu yoksa ön çekme mesafesi 5 metre yan bahçe 3.5 metre, arka çekme mesafesi ise yüksekliğin saçak payı artı ile yarısından oluşan mesafe yaklaşımı verilmelidir. Yani $\mathrm{H} / 2=(5 * 3+0.5) / 2=7.75$ metre olarak çekilir. Yüksekliğin yarısının çekilmesinde derinlikte minimum bina yapmayı engelleyecek mesafe şartı olursa asgari 3 metre çekilip arka bahçe mesafesi olarak verilir.

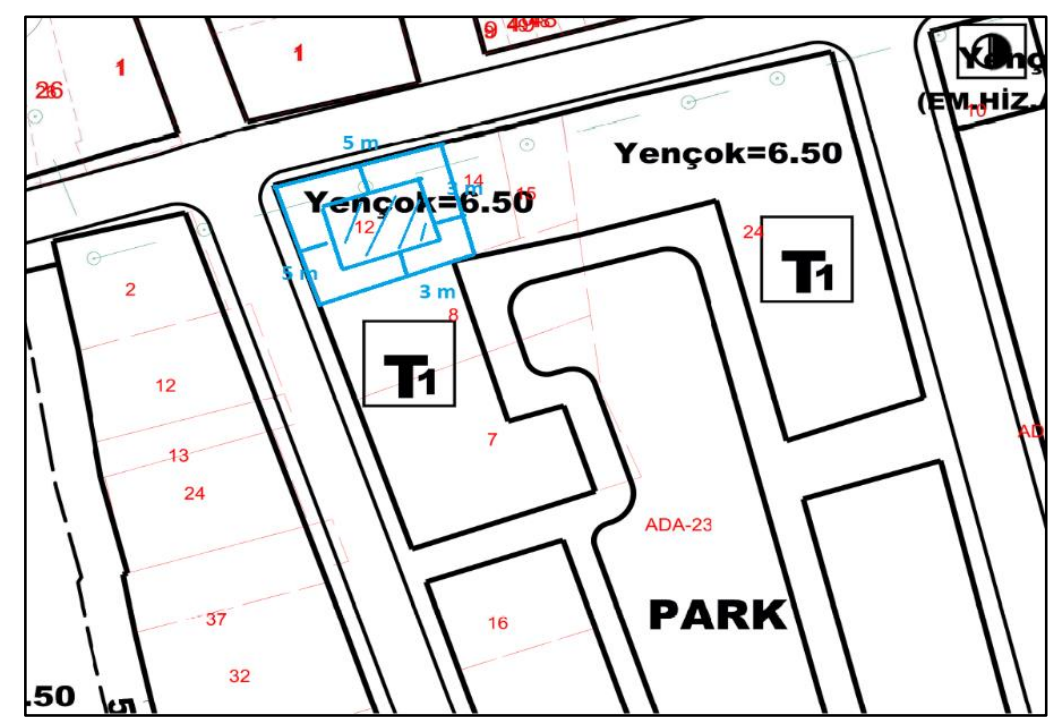

Şekil 6. İmar çap1 görüntüsü

Şekil 6.da, zemin artı bir yani 2 katlı dükkan yapımına izin verilen ticari bir imar adasında mesafe yaklaşımı ile yollara bakan taraftan ön bahçe mesafesi 5 er metre, yan bahçe mesafesi ise 3 metre çekilerek bina oturum alanı olan imar çapı gösterilmiştir. 


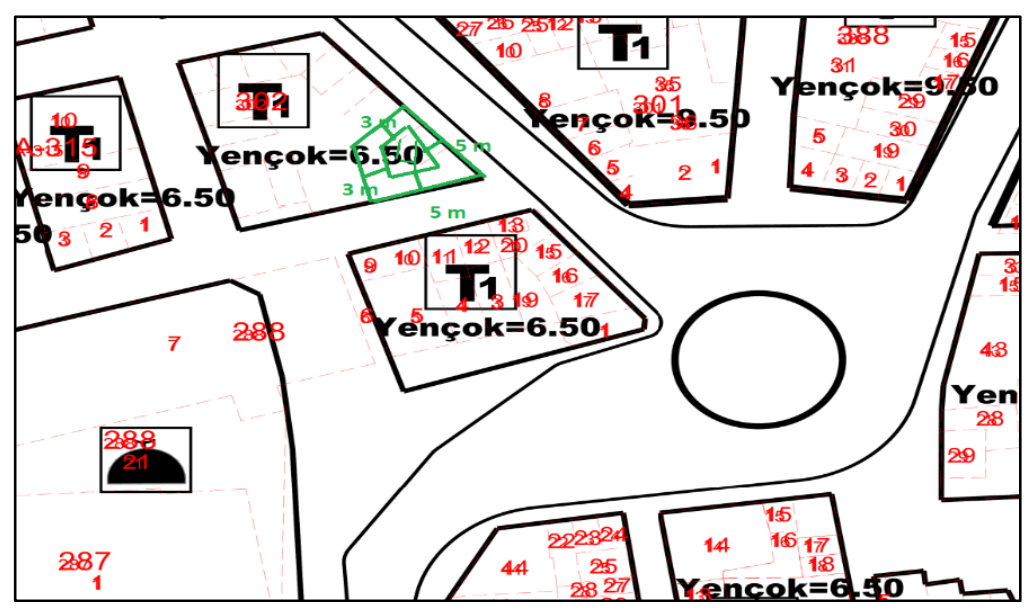

Şekil 7. İmar çap1 görüntüsü

Şekil 7.de, 6.50 metre yüksekliğine sahip 2 katlı ticari bir alanda köşe başı parselde bulunan taşınmaza mesafe yaklaşımı ile ön çekme mesafesi 5 er metre, yan bahçe mesafesi 3 er metre verilerek imar çapının nasıl verilmesi gerekliliği gösterilmiştir.

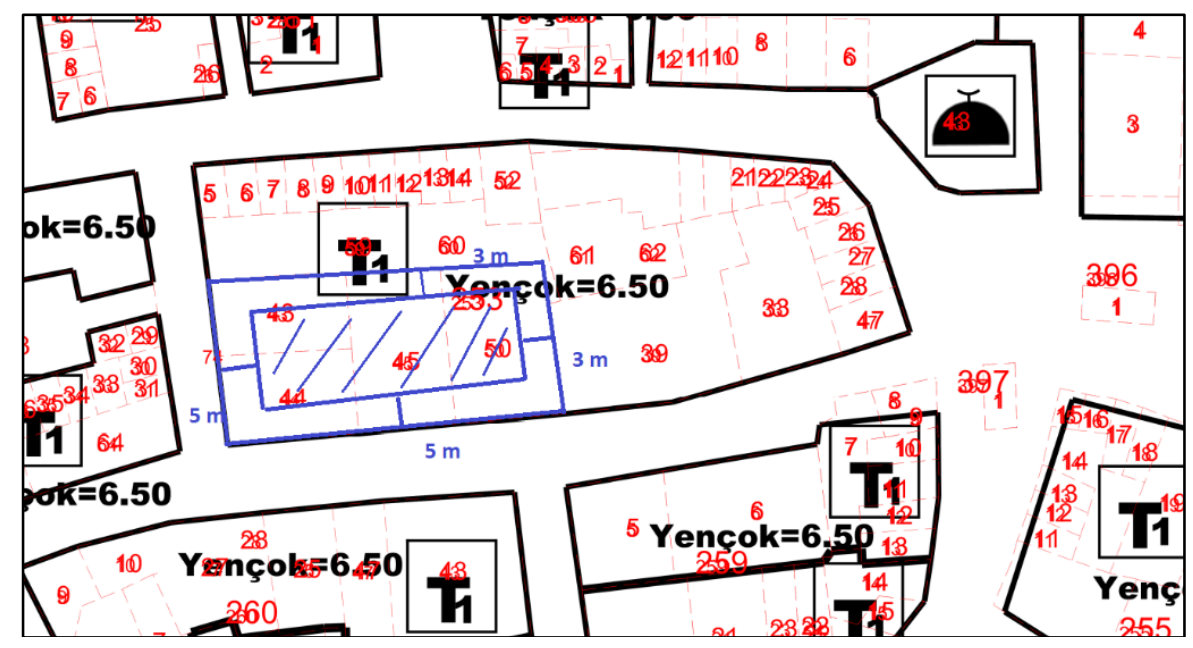

Şekil 8. İmar çap1 görüntüsü

Şekil 8.de, ilgili taşınmaz 4 tane kadastral parselin 15 ve 16. madde İmar Kanunu uygulaması ile birleştirilerek tek bir imar parseline dönüştürülüp, ticari amaçlı bina yapımı için ruhsat alabilmesi için öncelikle imar çapının yollara bakan kısımlarda 5 er metre, yan komşu parsellerden 3 er metre çekilerek nasıl mesafe yaklaşımı olacağ 1

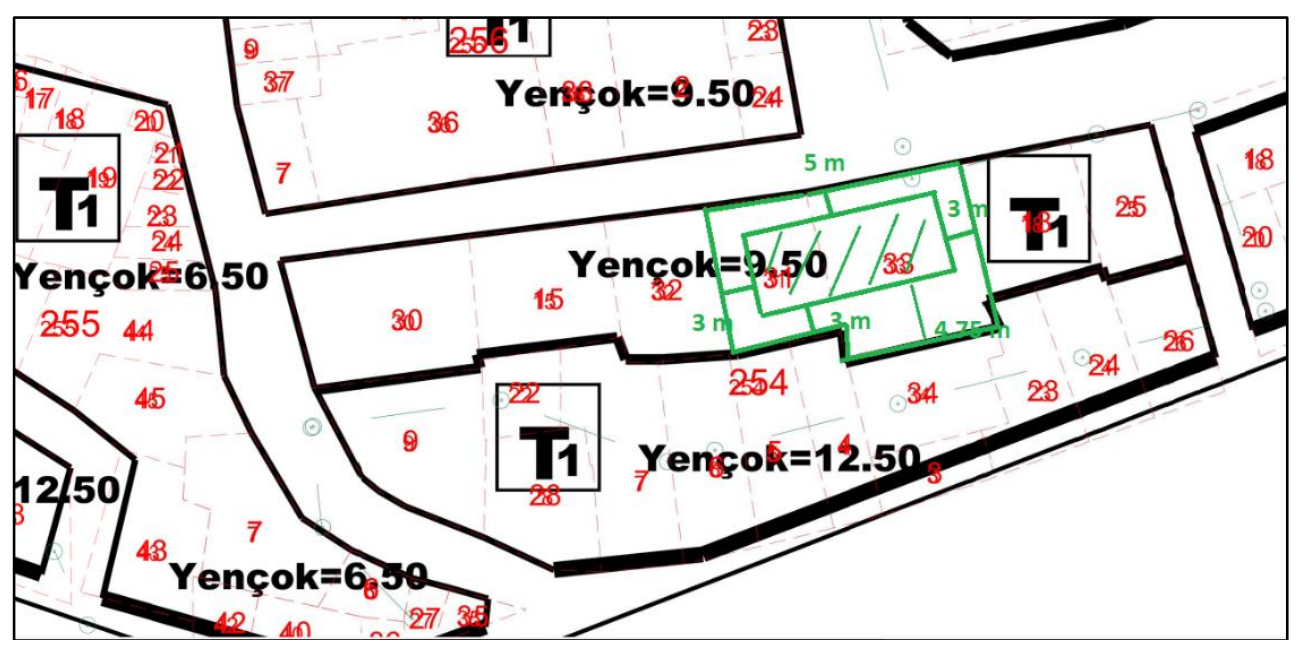

Şekil 9. İmar çap1 görüntüsü 
Şekil 9.da, maksimum 3 kata kadar müsaadeli bir alanda bulunan taşınmazın yola bakan tek cephesinden 5 metre, yan bahçe olarak komşu parsellere bakan tarafinda yapılaşma durumu yok ise 3 er metre derinlikte parselin durumu göz önünde bulunduğunda yetmeyeceği düşünülürse asgari 3 metre çekilerek tek bir noktasında yüksekliğin yarısı 4.75 metre çekilerek imar çapı verilmiştir.

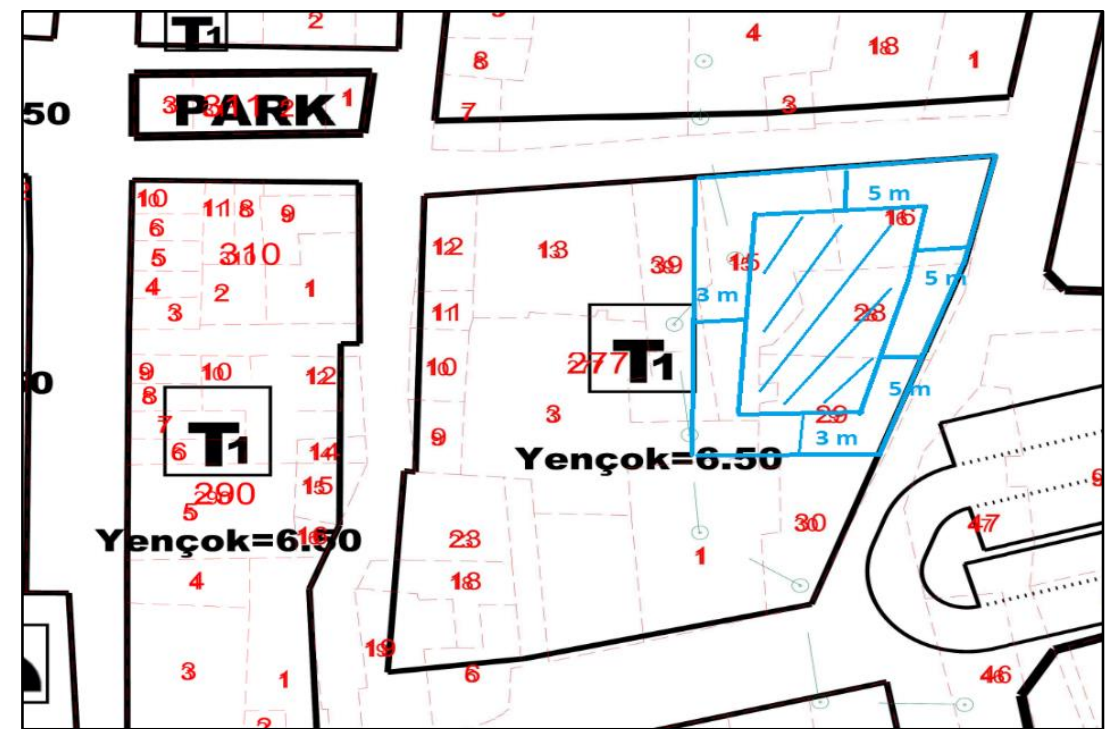

Şekil 10. İmar çapı görüntüsü

Şekil 10.da, bulunan taşınmaz birden fazla kırmızı kesikli olarak gösterilen tarla konumundaki parsellerin birleştirilmesi vasıtasıyla bir araya getirilerek imar parseli haline gelmiş, sonrasında taban oturum alanının belirlenebilmesi için mesafe yaklaşımı ile ön

\section{Sonuç ve Öneriler}

İmar planları nazım ve uygulama şeklinde ölçeklerine göre il, ilçe, belde gibi belediyelerin olduğu yerlerde yürürlüğe sokulup doğru şehircilik anlayışı ortaya konmaya çalışılır. $\mathrm{Bu}$ imar planı lejantlarında konut, konut ticaret, ticaret, sosyo-kültürel, spor tesisi, DOP alanları gibi imar adaları oluşturulur ki, kadastral parseller imar parsellerine bu adaların içerisine uygun şekilde atılması suretiyle dönüşümü yapılarak inşaat için ruhsat alabilirler. Konut alanlarındaki adalarda ise bölgenin içten dışa doğru açılımı yapılarak iç içe kümeleme ile bu parsellerin mesafe yaklaşımları verilerek bina oturumları uygun olsun. Bundan dolayı bölge merkezlerinde bitişik, yeni yerleşime açılacak yerlerde ise blok ve ayrık nizam gibi belirgin yapı nizamlarında konut imar adaları oluşturulur. Bu adalarda planlı tip imar yönetmeliği ve belediyelerin meclislerinden onaylı plan notlarına göre imar çapları nasıl verilmesi gerekliliği açıklanır. Çalışmadaki örneklerde farklı yapı nizamlarında imar parsellerine genel olarak nasıl imar çapı verilmesi gerekliliği gösterilerek uygun imar çapı gösterilmiştir. TAKS ve KAKS hesaplamaları ile mimari projelerde kullanılacak toplam emsal hesaplamaları da gösterilmeye çalışılarak doğru yapı oluşumu irdelenmiştir. Önerimiz ise imar çaplarının öncelikle imar adasındaki tüm parseller göz önüne alınarak diğer parsellerdeki üzerinde var olan yapılara dikkat edilerek kanun ve yönetmelikte belirtilen çekme mesafeleri ile mesafe yaklaşımları konveks geometrilerine uygun şekilde komşu parsellerini mağdur etmeden verilmelidir.

\section{Kaynaklar}

Aksay B (2005) Hukuki Açıdan Arazi ve Arsa Düzenlemesi. Makro yayınlar1, Ankara.

Ayranc1, İ. (2013). Metropolitan Alanlarda Planlama - Kentsel Gelişimin Yönetimi İlişkisi ve Bir İzleme Değerlendirme Model Önerisi. (Doktora Tezi), İstanbul Teknik Üniversitesi, taraflarından 5 er metre, yan taraflarından ise 2 katlı ticari alan olduğundan 3 er metre çekilerek imar çapları belirlenmiştir.

Fen Bilimleri Enstitüsü.

Bıyı, C., ve Uzun, B., 1997. 3194/18. Madde Uygulamalarında Süre-Maliyet Analizlerinin Somut Bir Örnek Üzerinde İncelenmesi, İmar Planı Uygulama Teknikleri, JEFOD yayın No: 1, Trabzon, $123 \mathrm{~s}$.

Çelik K., (2006), "Planlama ve İmar Kanunu Uygulaması Arazi ve Arsa Düzenlemesi", 1. Bask1, Devran Matbaacilık.

Dragomir, S.S., 2001. On the Hadamard's inequality for convex functions on the coordinates in a rectangle from the plane, 5 (4), 775-788.

Ergen C., (2006), "Açıklamalı-İçtihatlı En Son Değişikliklerle Arazi ve Arsa Düzenlemeleri”, 2. Baskı, Seçkin Yayıncıllk.

Frizzell R (1979) The Valuation of Rural Property, Lincoln College, New Zeland.

İmar Kanunu, (2019). Resmi Gazete, Cilt:24. Sayfa:1-378.

Kaplan, M., 2016. Koordinatlarda Geometrik Konveks Fonksiyonlar İçin İntegral Eşitsizlikler, Yüksek lisans tezi, Ağrı İbrahim Çeçen Üniversitesi Fen Bilimleri Enstitüsü.

Karaağaç, M.F., 2019. 3194 Sayılı İmar Kanununun 18. Maddesinin Uygulanmasında Karşılaşılan Sorunlar ve Çözüm Önerileri, Yüksek lisans tezi.

Karavelioğlu C., (2002), “ İmar Kanunu 18. Madde Uygulaması”, 1. Bask1, Karavelioğlu Hukuk Yayınevi.

Latif, M.A. and Alomari, M., 2009. Hadamard-type inequalities for product two convex functions on the co-ordinates, International Mathematical Forum, 4 (47), 2327- 2338.

Taşkaya, S., (2019). Yerel Yönetimlerde İmar ve Şehircilik Faaliyetleri Üzerine Bir Araştırma, 2014-2019 Yılları Arası Belediyecilik, Elazığ İli Örneği. Uluslararası Doğu Anadolu Fen Mühendislik ve Tasarım Dergisi, 1(1), 14-28.

Taşkaya, S., (2019). İnşaat Yapım İzni İçin Temel Nokta Olan İmar Çapları Üzerine Bir Araştırma, Uluslararası Doğu Anadolu Fen Mühendislik ve Tasarım Dergisi, 1(2), 142-153. 
Taşkaya, S., Taşkaya, S., (2019). Çok Katlı Yapıların ANSYS Paket Yazılımında Workbench Modülü Kullanılarak

Ölçümlendirilmesi ve Prototip Analizlerinin İncelenmesi, Uluslararası Mühendislik, Tasarım ve Teknoloji Dergisi 1(2): 51-63.

Taşkaya, S., Taşkaya, S., (2019). İki Katlı Binanın Ansys Workbench Yazılımında Koordinat Noktalarının Ölçümlendirilmesi ve Kirişlerdeki Gerilmelerin İncelenmesi, International Journal on Mathematics, Engineering and Natural Sciences, 2019, vol:9 page:40-57.

Taşkaya, S., Sesli, F.A., (2019). Gürültü Kirliliğinde Stratejik ile Lokal Konumsal Verilerin Power Testi ile Analizi, Elazığ İli İzzetpaşa Örneği, Uluslararası Doğu Anadolu Fen Mühendislik ve Tasarım Dergisi ISSN: 2667-8764, International Journal of Eastern Anatolia Science Engineering and Design ( IJEASED) (2019) 1(1):1-13.

Terzioğlu, A.G., 2015. Çok Hisseli Parsellerde İmar Planı Uygulamasi: Sultanbeyli Örneği, Yüksek lisans tezi.

Uzun, B., 2009. Using Land Readjustment Method As An Effective Urban Land Development Tool In Turkey, Survey Review, 57 70.

Ünal, Y. (2008). Türk Şehir Planlama ve İmar Mevzuatının Kentsel Dönüșümü. Yetkin Yayınları.

Yomralıoglu T., (1992), “Arsa ve Arazi Düzenlemesi İçin Yeni Bir Uygulama Şekli”, 73. Baskı, Harita ve Kadastro Mühendisleri Odası Dergisi. 